\title{
Fracture prediction during sawing of DC cast high strength aluminium alloy rolling slabs
}

\author{
J.-M. Drezet ${ }^{* 1}$, O. Ludwig ${ }^{1}$, C. Jacquerod ${ }^{2}$ and E. Waz ${ }^{3}$
}

The semicontinuous direct chill (DC) casting of large cross-section rolling sheet ingots of high strength aluminium alloys (2xxx and 7xxx series) gives birth to high residual (internal) stresses generated by a non-uniform cooling. These stresses must be relieved by a thermal treatment in order to be able to safely saw both ingot butt and head. Otherwise, saw pinching or blocking might occur due to the compressive residual stresses, or cut parts might be brutally released by erratic propagation of a crack ahead of the saw groove thus injuring people or damaging equipment. As these high added value ingots must be produced in secure conditions, a better control of the sawing procedure is required, which could allow the suppression of the thermal treatment and therefore save time and energy. By studying the stress build-up during casting and cooling then the stress relief during sawing operations of rolling sheet ingots, key parameters for the control and optimisation of the processing steps can be derived. To do so, the DC casting of the high strength AA2024 alloy is modelled with ABAQUS 6.5 with special attention to the thermomechanical properties of the alloy. The sawing operation is then simulated by removing mesh elements such as to reproduce the progression of the saw in the ingot. Preliminary results showing the stress relief during sawing accompanied by the risk of saw blocking due to compression or initiating a crack ahead of the saw are analysed with an approach based on the rate of strain energy release.

Keywords: Aluminium alloys, DC casting, Residual stress, Sawing, Numerical model

\section{Introduction}

In the fabrication of aluminium rolled products, the first step is the semicontinuous casting of a rectangular ingot. The most commonly used process is the direct chill (DC) casting. ${ }^{1}$ This one involves large thermally induced strains that lead to several types of casting defects (e.g. distortions, cracks, porosity). Among them, the permanent deformation of the ingot butt and head requires that the extremities of the slab are sawed before the homogenisation treatment and hot rolling. The sawing operation remains delicate since, depending on the alloy and the technology used to cast, microcracks can be present and may propagate during sawing due to the redistribution of residual stresses in the ingot. In particular, in large cross-section rolling sheet ingots of high strength alloys (2000 and 7000 series), these internal stresses can be high enough to cause the macroscopic fracture of the ingot during sawing, if not during casting or cooling (see Fig. 1). Parts can be ejected and injure

${ }^{1}$ Computational Materials Laboratory, School of Engineering, Ecole Polytechnique Fédérale de Lausanne, Station 12, CH-1015 Lausanne, Switzerland

${ }^{2}$ Alcan Aluminium Valais SA, CH3960 Sierre, Switzerland

${ }^{3}$ Alcan Centre de Recherches de Voreppe BP27 F38341 Voreppe cedex, France

*Corresponding author, email jean-marie.drezet@epfl.ch people or damage equipment. To avoid such harmful events, the cutting of the ingot butt is performed after a thermal heat treatment, which relaxes the residual stresses. Sawing the ingot securely right after casting would be particularly attractive because of the possible time and energy saving if the relaxation treatment is skipped. To this aim, an innovative way of sawing the ingot that can lead to a gradual relaxation of internal stresses without fracture must be proposed. Therefore, a numerical thermomechanical simulation of butt sawing has been undertaken to compute the stress build up during casting and subsequent cooling and the stress release during sawing. Special attention was paid to the mechanical description of the alloy from the liquid state down to room temperature.

The computation of stresses during DC casting of aluminium alloys has been the scope of several studies since the $1990 \mathrm{~s}^{2-5}$ and is a well established technique nowadays. On the other hand, the interactions of the internal stresses field with a population of stress raisers such as inclusions, pores, microcracks, oxide patches can lead to the local fracture of the ingot during casting (cold cracking), cooling or sawing. This has been considered by Boender et al. ${ }^{6}$ who assumed brittle fracture during casting and compared the stress intensity factor induced by the above mentioned defects to the fracture toughness $K_{\mathrm{I}}^{\mathrm{c}}$ of the alloy. Such an approach 


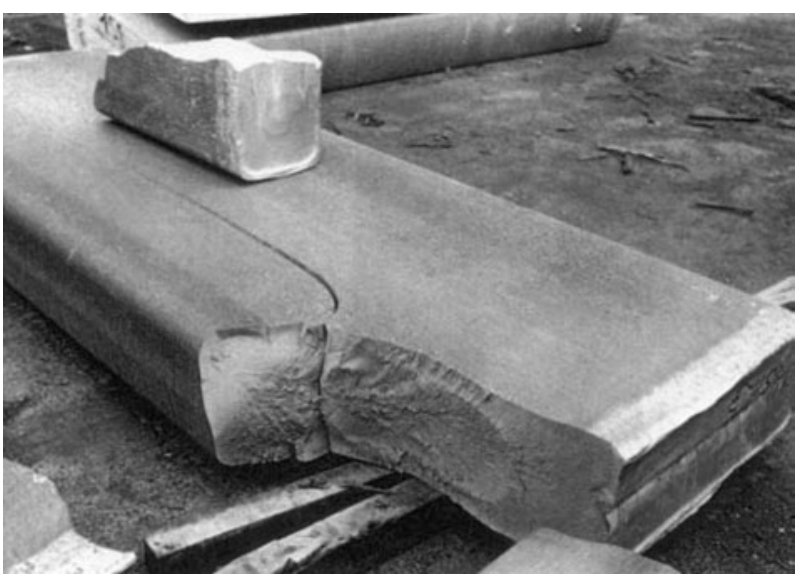

1 High strength aluminium alloy slab that cracked spontaneously during casting (cold cracking): $500 \mathrm{~kg}$ part that broke apart from ingot was projected several tens meters away; similar events can occur during sawing (photo courtesy Alcan)

has been further extended by Ludwig et al. ${ }^{7}$ to sawing when analysing the risk of crack initiation and propagation ahead of the saw. In the present work, a new fracture approach based on the strain energy release is used to assess the risk of cracking during sawing. To illustrate the approach, the high strength AA2024 aluminium alloy will be considered. The composition of the alloy is presented in Table 1 together with the solidus and liquidus temperatures computed by the software ProPHASE, based on a model proposed by Sigli et $a .^{8}$

\section{Rheological behaviour of AA2024 alloy}

One of the prerequisite to the modelling of the DC casting is the description of the mechanical behaviour of the alloy from the liquid state down to room temperature. This behaviour yields the level of stress generated during the process by the non-uniform cooling conditions.

\section{Constitutive equation}

The AA2024 alloy is modelled as an elastic material with low Young's modulus $(0.5 \mathrm{GPa})$ above its coherency temperature (liquid-like behaviour), $612^{\circ} \mathrm{C}$ corresponding to a solid fraction of $65 \%$ for a grain refined structure. Under the coherency temperature, one has to address the effect of strain and strain rate on stress formation: the alloy is treated as an elastoviscoplastic solid material exhibiting strain hardening. The constitutive equation governing this solid-like behaviour is given by a modified Ludwik's equation $^{9}$

$$
\bar{\sigma}=K(T)\left(\gamma_{\mathrm{p}}+\gamma_{\mathrm{p}}^{0}\right)^{\mathrm{n}(\mathrm{T})}\left(\frac{\dot{\varepsilon}_{\mathrm{p}}}{\dot{\varepsilon}_{\mathrm{p}}^{0}}\right)^{\mathrm{m}(\mathrm{T})}
$$

with

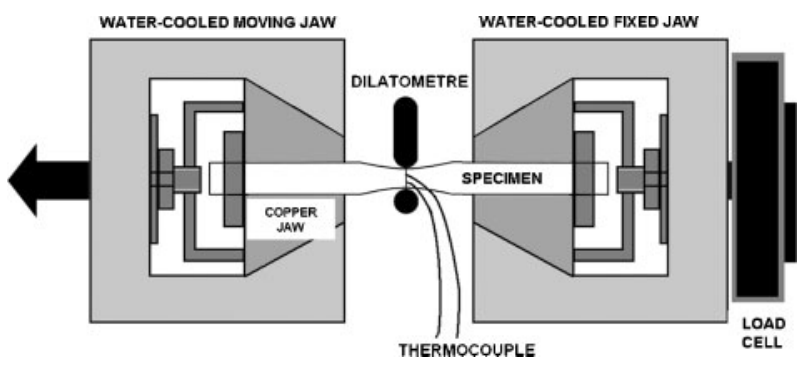

2 Schematic representation of Gleeble apparatus

$$
\gamma_{\mathrm{p}}=\int_{\mathrm{T}<\mathrm{T}_{0}} \dot{\varepsilon}_{\mathrm{p}} \mathrm{d} t
$$

where $\bar{\sigma}$ is the von-Mises equivalent stress, and $\dot{\varepsilon}_{\mathrm{p}}$ is the equivalent inelastic strain rate. The internal variable $\gamma_{\mathrm{p}}$ is equal to the cumulated inelastic strain from a temperature $T_{0}$ down to the current temperature. Therefore, the effect of the plastic strain on the stress is neglected above $T_{0}$, which corresponds roughly to an annealing temperature and above which dynamic recovery of the structure is very efficient. $T_{0}=423^{\circ} \mathrm{C}$ for the alloy under study. The constant $\gamma_{\mathrm{p}}^{0}$ is taken equal to $0 \cdot 001$ and $\dot{\varepsilon}_{\mathrm{p}}^{0}$ is a reference strain rate taken equal to $1 \mathrm{~s}^{-1} . K(T), m(T)$ and $n(T)$ are continuous functions of the temperature $T$. The first one is the consistency of the alloy and has the unit of a stress $(\mathrm{MPa})$. The second one is the strain rate sensitivity, and the third one is the strain hardening power coefficient. The Ludwik's equation is very well suited to describe the transition from time independent plasticity at low temperatures to time dependent plasticity (viscoplasticity) at high temperatures.

\section{Experimental determination of rheological parameters}

Magnin et al. ${ }^{9}$ studied the mechanical behaviour of as cast $\mathrm{Al}-4.5 \mathrm{wt}-\% \mathrm{Cu}$ and fitted the measured curve to obtain the temperature dependence of the three rheological function $K, m$ and $n$. For the AA2024 industrial alloy, these functions were experimentally determined by tensile tests carried out at several temperatures and strain rates on a 1500 Gleeble machine. A schematic representation of the experimental apparatus is shown in Fig. 2. This machine uses intense electrical current to heat the tensile specimen by the Joule effect, and water cooled jaws to assure a high heat extraction at each side. Thus, only a small section at the centre is held at the prescribed temperature, and stress and strain rate are varying in the axial direction of the specimen due to the temperature dependency of the flow stress. During the test, the temperature in the jaws increases slightly. The associated thermal expansion is experimentally undistinguishable from the elongation caused by deformation, if the elongation of the specimen is to be used for determining the strain. Due to these phenomena, the diameter is measured at the specimen centre by an extensometer. This signal is used to determine the strain and strain rate undergone by the sample. In order to

Table 1 Composition and solidification temperatures of AA2024 alloy, wt-\%

\begin{tabular}{llllllllll}
\hline Alloy & Si & Fe & Zn & Cu & Mg & Mn & Cr & Solidus temperature, ${ }^{\circ} \mathbf{C}$ & Liquidus temperature, ${ }^{\circ} \mathbf{C}$ \\
\hline AA2024 & 0.15 max. & 0.30 max. & 0.20 max. & 4.30 & 1.45 & 0.72 & 0.05 & 505 & 638 \\
\hline
\end{tabular}




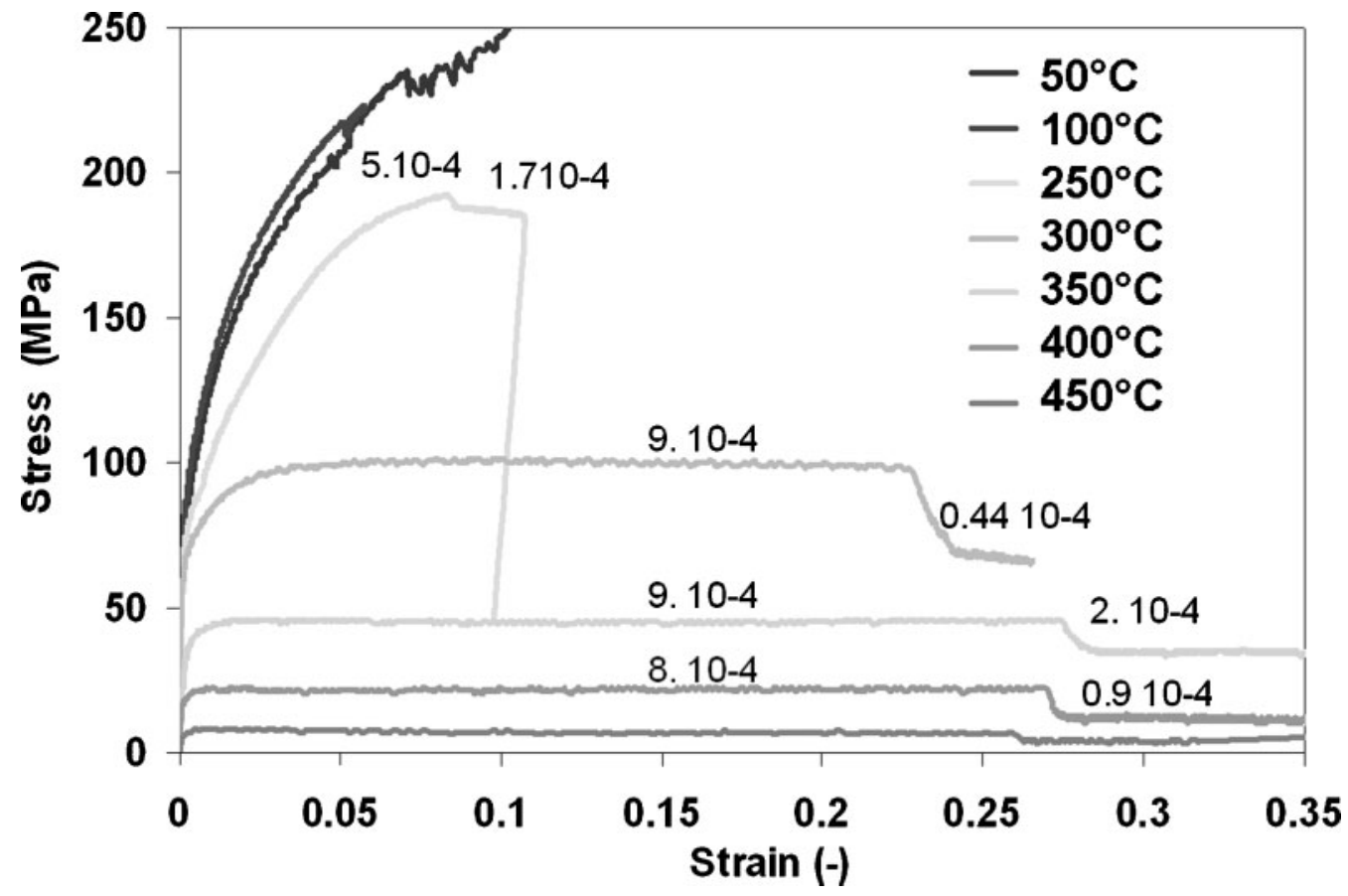

3 Typical stress versus strain curves obtained from Gleeble tests at different temperatures and strain rates for AA2024 alloy: strain rates are indicated in $s^{-1}$

make sure that the position of maximum straining is at the very specimen centre where the controlling thermocouple is fixed, a slightly curved specimen geometry as indicated in Fig. 2 is used. The length of the specimen (initially $95 \mathrm{~mm}$ between the jaws) is chosen to obtain the low strain rates characteristics of thermally induced deformations in DC casting. A constant jaw velocity is applied.

Due to a fast heating of the specimen, it is possible to follow accurately a desired thermal history. This can be used to impose a heat treatment to the specimen and therefore to control the microstructure before the tensile test. To be representative as much as possible of the microstructure and thermal history of the alloy during DC casting, a reheating profile was determined by Magnin et al. ${ }^{9}$ These authors recommended performing a 'sensitised' test with a short holding time $(10 \mathrm{~s})$ at $500^{\circ} \mathrm{C}$ before cooling down to the test temperature. For test temperatures above $500^{\circ} \mathrm{C}$, a fast heating (heating rate of $100^{\circ} \mathrm{C} \mathrm{s}^{-1}$ ) is applied. For the AA2024 alloy, the holding temperature was lowered to $450^{\circ} \mathrm{C}$ to avoid melting during the test. Samples for rheological testing were machined out from DC cast billets ( $210 \mathrm{~mm}$ in diameter) provided by ALCAN.

Once the test is performed, the values of the measured force $F$ and diameter $D$ allow calculating the tensile stress and strain on the material

$$
\begin{aligned}
\sigma & =\frac{4 F}{\pi D^{2}} \\
\varepsilon_{\mathrm{p}} & =-2 \ln \frac{D}{D_{0}}
\end{aligned}
$$

Figure 3 shows typical results obtained on the AA2024 alloy. Obviously, the stress values decrease with increasing test temperature. At temperature lower than $300^{\circ} \mathrm{C}$, the behaviour of the alloy is insensitive to the applied strain rate, but presents significant strain hardening. At higher temperatures, the strain hardening is negligible, but the stress response becomes rate dependent (viscoplastic behaviour). At intermediate temperatures $\left(250-300^{\circ} \mathrm{C}\right)$, both strain hardening and rate effects are present. Equation (1) allows taking into account these phenomena.

After fitting equation (1) to the experimental curve, one can determine the value of the rheological parameters $K, m$ and $n$ at each test temperature. Then, each parameter can be fitted to a continuous function of the temperature, such as a fourth order polynomial for the $\mathrm{Al}-4 \cdot 5 \mathrm{Cu}$ alloy ${ }^{10}$ or sigmoid functions ${ }^{11}$ such as

$$
K(T)=a_{\mathrm{K}}\left[1-\tanh \left(\frac{T-c_{\mathrm{K}}}{b_{\mathrm{K}}}\right)\right]
$$

where $a_{\mathrm{K}}, b_{\mathrm{K}}$ and $c_{\mathrm{K}}$ are constant parameters relative to $K(T)$. Similar fits are performed on $m(T)$ and $n(T)$.

\section{Computation of stress build-up during DC casting}

\section{Numerical model of DC casting}

The DC casting process is simulated with the help of a coupled thermomechanical model implemented in the finite element code ABAQUS 6.5 and based on the work of Drezet et al. ${ }^{2}$ The finite element mesh is made out of $30 \mathrm{~mm}$ high layers of brick elements with eight integration points. The coordinate system is fixed with respect to the ingot and the incoming flow of liquid metal is modelled through the activation of successive layers at a rate which corresponds to the casting speed $\left(60 \mathrm{~mm} \mathrm{~min}^{-1}\right)$ and at a temperature set to that of the incoming metal $\left(670^{\circ} \mathrm{C}\right)$. The lateral cooling conditions are translated along the external faces of the slab according to the casting speed. The thermal boundary conditions account for primary cooling through the mould, air gap formation and secondary cooling when the water hits the ingot and flows along its surface. ${ }^{12}$ The DC casting of a $1200 \times 500 \mathrm{~mm}$ rolling sheet ingot is simulated with a total cast length of $1000 \mathrm{~mm}$. Although the ingot presents two planes of symmetry, the computation domain represents the whole ingot as sawing 


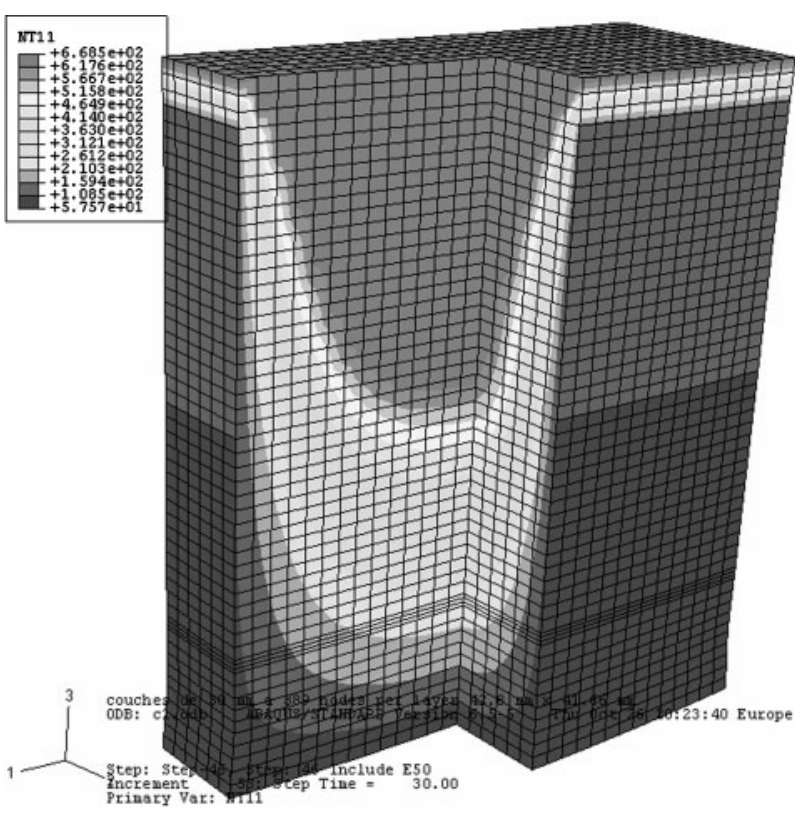

1 width direction; 2 thickness direction; 3 casting direction 4 Temperature field during casting, view of symmetry planes

itself does not respect these two symmetries. The mesh is refined near the saw plane where three layers $10 \mathrm{~mm}$ in thickness are present. Figure 4 shows the temperature field during casting. For better visibility, one-fourth of the ingot is removed. This allows seeing the liquid pool that forms during casting.

\section{Stress state during DC casting}

The law given in equation (1) and identified with the help of the Gleeble tests is implemented in ABAQUS $6 \cdot 5$ using the subroutine CREEP. Although it does not model properly the behaviour of the partially solidified 'mushy zone' of the casting, which would require the use of a more complex model, ${ }^{13}$ it is sufficient to model the formation of stresses in the solid state and does not imply excessive computation time. The mechanical properties of the AA2024 alloy in its solidification range are inspired from the work of Spittle et al. ${ }^{14}$ The thermophysical properties, such as thermal conductivity and specific heat, and the solidification path of the alloy were calculated by the software ProPHASE. ${ }^{8}$

Figure 5 shows the $\sigma_{\mathrm{XX}}$ stress field (normal stress along $X$ direction) during casting. The generally observed trends are retrieved. A large liquid pool is still present at the top of the ingot and rather large tensile stresses appear in the solidified shell right in the secondary cooling zone. On the contrary, at the bottom (coldest part), the shell is in a compression state and the core is in a tension state. This is because the cold shell, which is already at room temperature, hinders the contraction of the core region, which is still hot. This effect is known as the 'skin-core' effect reported by Drezet and Rappaz ${ }^{15}$ and also observed during the quenching of heat treatable alloys. ${ }^{16}$ The high tensile stresses $(\sim 100 \mathrm{MPa})$ in the core region and in the secondary cooling zone can be at the origin of the formation of cracks during casting. ${ }^{6}$
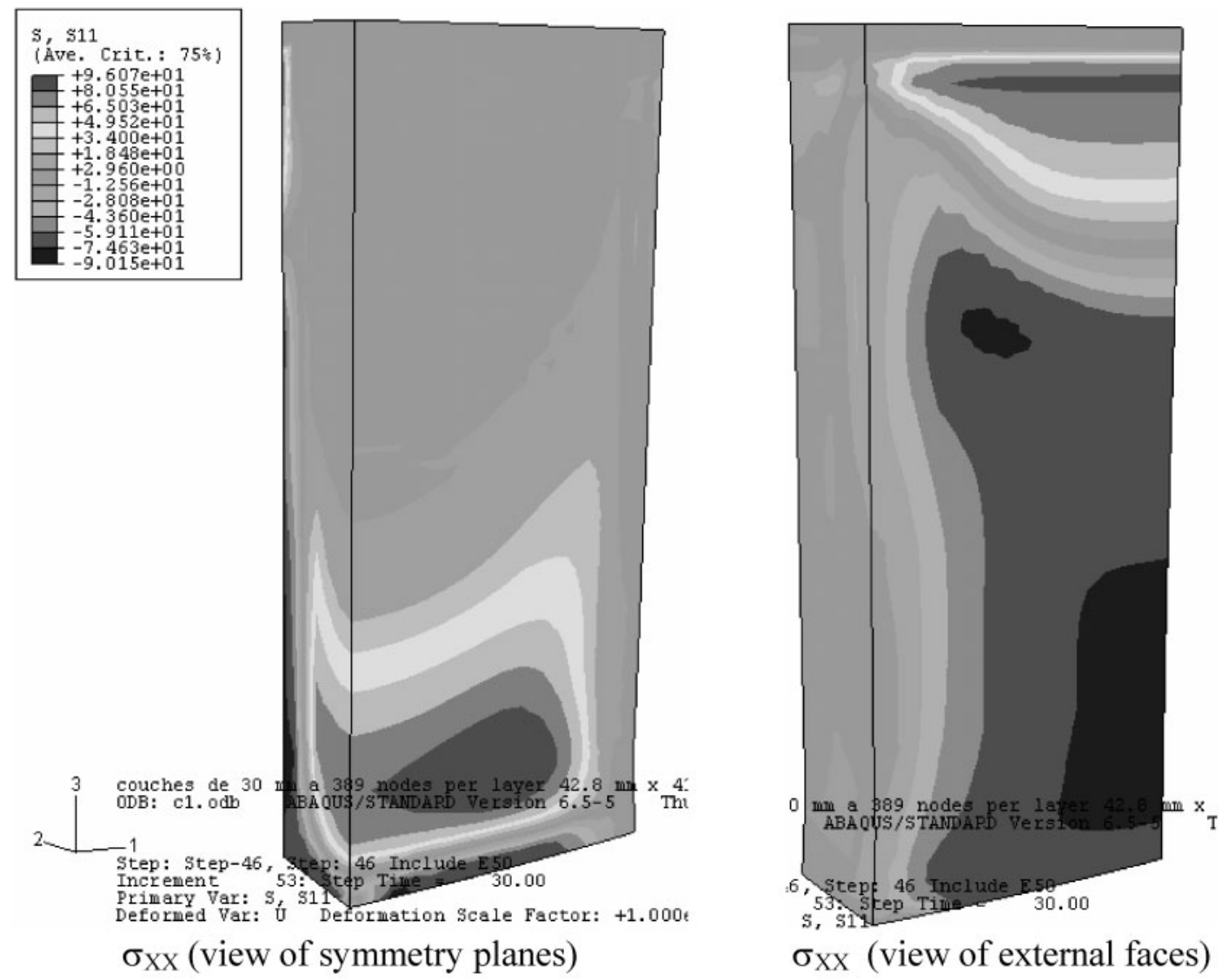

5 Normal stresses along $X$ directions $\left(\sigma_{X X}\right)$ at end of casting, before cooling 

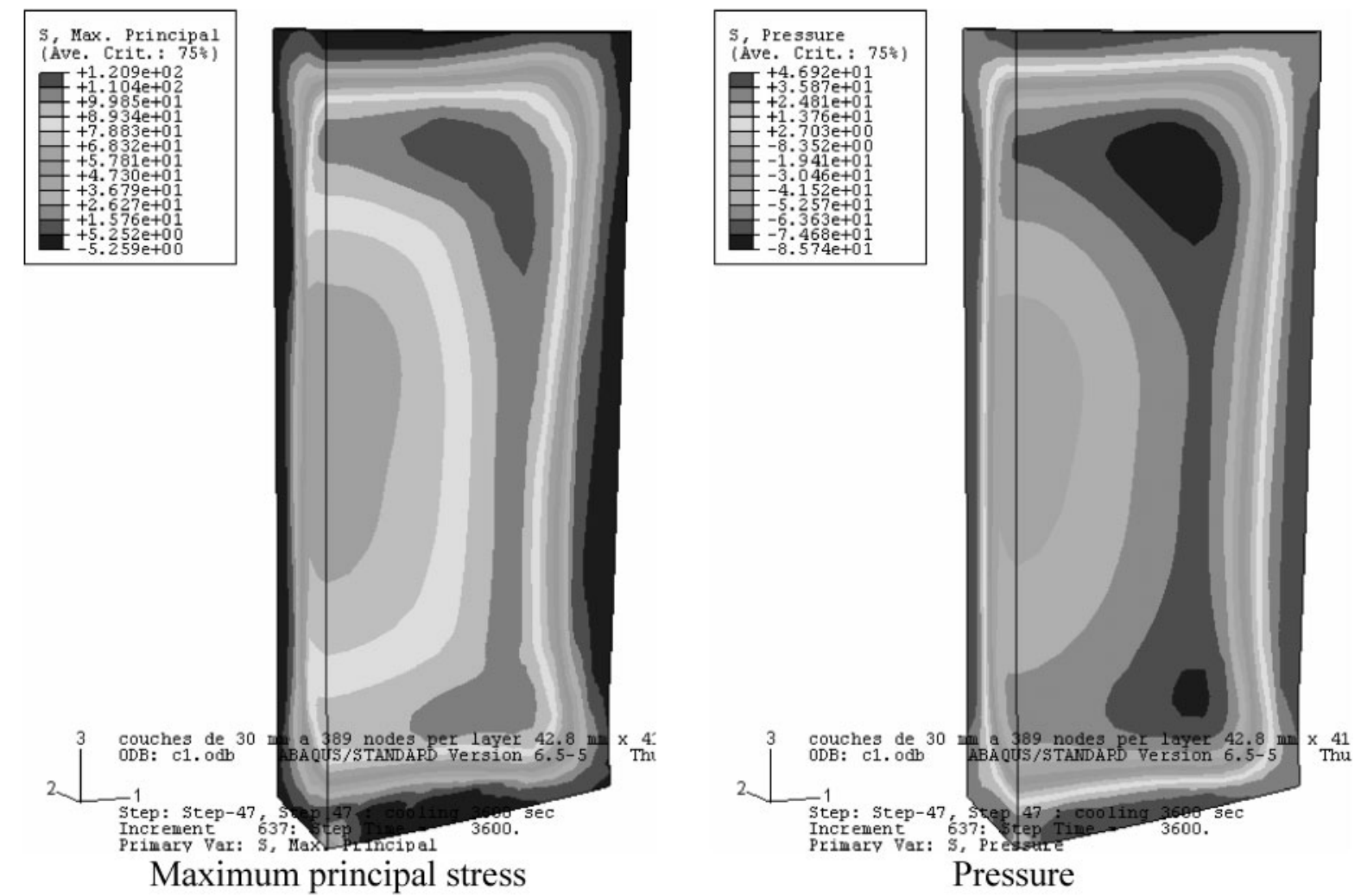

Pressure

6 Maximal principal stress and pressure fields after cooling (view of symmetry planes)

\section{Stress state after cooling (residual stresses)}

After the simulation of $3600 \mathrm{~s}$ of cooling, the internal stress field before sawing is obtained. Figure 6 shows the maximum principal stress and the pressure $\left(p=-1 / 3 \sigma_{\mathrm{ii}}\right)$ in the symmetry planes of the rolling sheet ingot. The skin of the ingot appears to be in a compressive stress state whereas the core is in a triaxial tensile stress state (the three principal stresses are positive). Figure 6 shows that after the transient start-up phase, the stress state becomes independent of the cast length (steady state) before varying again (transient end phase). It clearly appears that the two transient phases, start-up and end, leads to the formation of high stresses. The sawing of the rolling sheet ingot will take place precisely in these regions of high stresses.

Before the computation of sawing per se is presented, the approach based on the strain energy release and adopted to study the risk of fracture is explained in the following section.

\section{Strain energy release approach}

During the sawing of the ingot butt or head, the saw groove can open due to tensile stresses or may close and block the saw when compressive stresses are present. In any case, as the saw moves forward, residual stresses and strains are relaxed and stored strain energy is decreased. In tensile conditions, an unstable propagation of the groove considered as a macrocrack is possible and can lead to the fracture of the ingot.

An approach inspired by classical fracture mechanics is adopted to calculate the strain energy release rate during the simulation of sawing and to compare it to a critical value. The fracture of the ingot is assumed to originate in the groove made by the saw that propagates due to the opening of its lips (mode I). Considering the notch as a propagating crack, the time derivative of the strain energy balance ${ }^{17-19}$ for the whole ingot is written as

$$
\frac{\mathrm{d}(I E)}{\mathrm{d} t}+\dot{K}=P(x)+\dot{Q}-2 \gamma \cdot \dot{A}
$$

where $I E$ is the total strain energy (elastic + inelastic) of the ingot; $\dot{K}$ is the time derivative of the kinetic energy of the ingot; $P(x)$ is the work of the external forces acting on the ingot. As there is no external forces in this case, $P=0 ; \dot{Q}$ is the heat rate, and is neglected here since the sawing operation is considered as an adiabatic process; $2 \gamma \cdot \dot{A}$ is the interfacial energy rate to create a surface of area $\mathrm{A}$; and $\gamma$ is the surface energy of the alloys.

The condition for the saw groove to propagate in an unstable manner is that the kinetic energy of the ingot increases

$$
\dot{K}>0, \text { i.e. }-\frac{\mathrm{d}(I E)}{\mathrm{d} t}>2 \cdot \gamma \dot{A}
$$

this can be rewritten as

$$
-\frac{\partial I E}{\partial A}>2 \gamma
$$

in fracture mechanics, the rate of strain energy release, $G$, is written as $G=-\frac{\partial I E}{\partial A}$. Very few data are available for the surface energy $\gamma$. In practice, the strain energy release rate $G$ is compared to a critical value $G^{\mathrm{c}}$ which depends on the stress state

$$
\begin{aligned}
& G^{\mathrm{c}}=\frac{K_{\mathrm{I}}^{2}\left(1-v^{2}\right)}{E} \quad \text { (in plane strain condition) } \\
& G^{\mathrm{c}}=\frac{K_{\mathrm{I}}^{2}}{E} \quad(\text { in plane stress condition })
\end{aligned}
$$



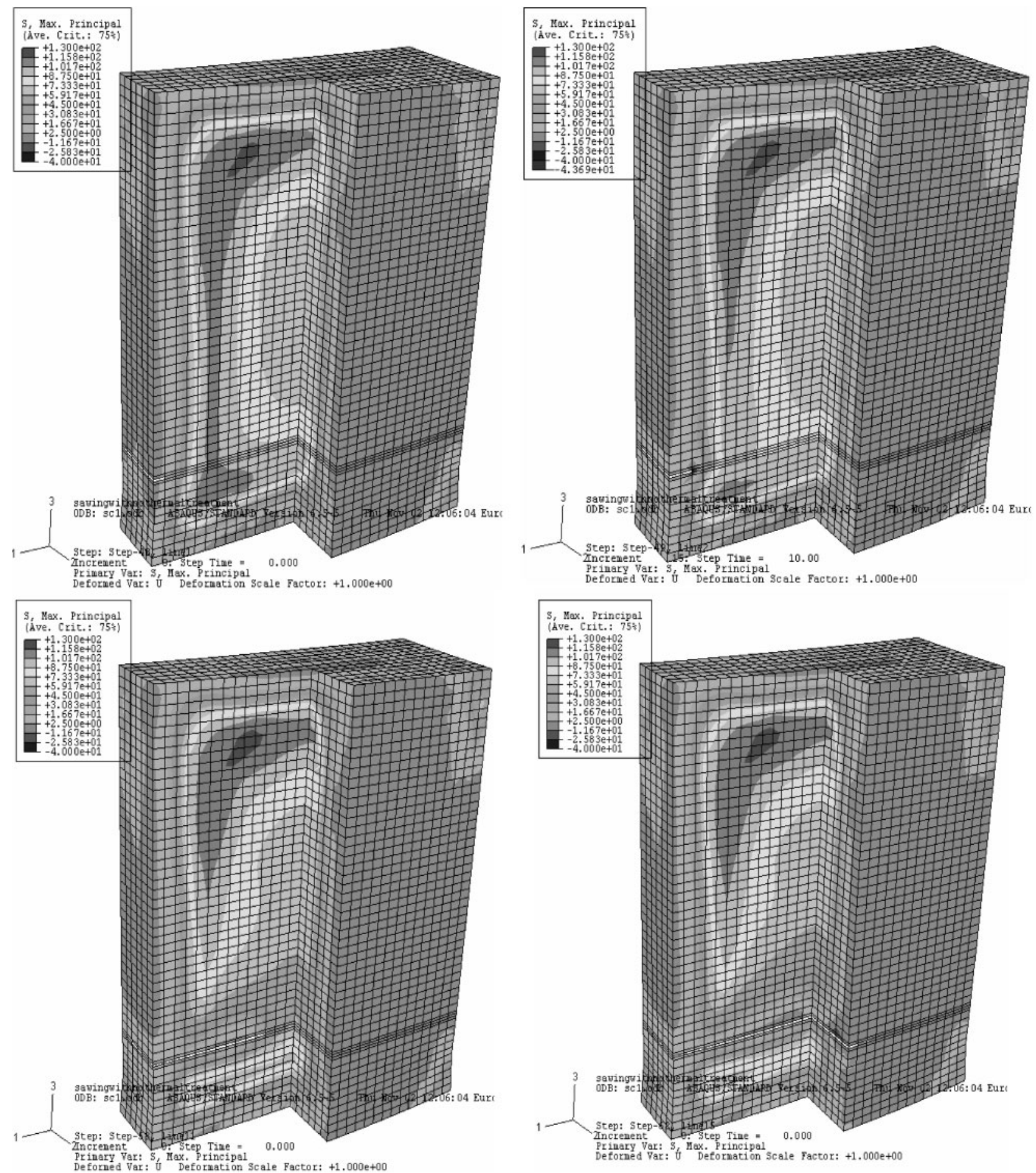

7 Evolution of maximum principal stress during sawing: saw groove is presented in white

where $E$ and $v$ are the Young's modulus and Poisson's ratio respectively. The numerical simulation of sawing provides an evaluation of the strain energy release rate. The strain energy $I E$ is a direct output of a stress analysis in ABAQUS 6.5. At each time step, some elements are removed, and an area $\Delta A$ is created. The strain energy release rate is estimated by

$$
G \approx-\frac{\Delta I E}{\Delta A}
$$

two conditions are necessary for fracture to occur. First, the saw groove must open, i.e. the distance $D$ between the two lips of the groove must increase: $\Delta D>0$. Second, the strain energy must be higher than the critical value
$G>G^{\mathrm{c}}$. Considering the measurements of Paramatmuni et al. ${ }^{20} K_{\mathrm{I}}^{\mathrm{c}}$ ranges from 15 to $35 \mathrm{MPa} \mathrm{m}{ }^{1 / 2}$ for the AA2024 alloy. Taking a Young's modulus of $70 \mathrm{GPa}$, this gives $G^{\mathrm{c}}$ values ranging from 3 to $17 \mathrm{~kJ} \mathrm{~m}^{-2}$.

\section{Modelling of sawing}

\section{Evolution of stresses during transverse sawing}

The transverse sawing, i.e. sawing the ingot from one short side to the other one along the width direction, right after casting, i.e. without any thermal treatment, is simulated and the strain energy release is computed together with the opening of the saw lips. The sawing is simulated numerically by removing successive rows of 


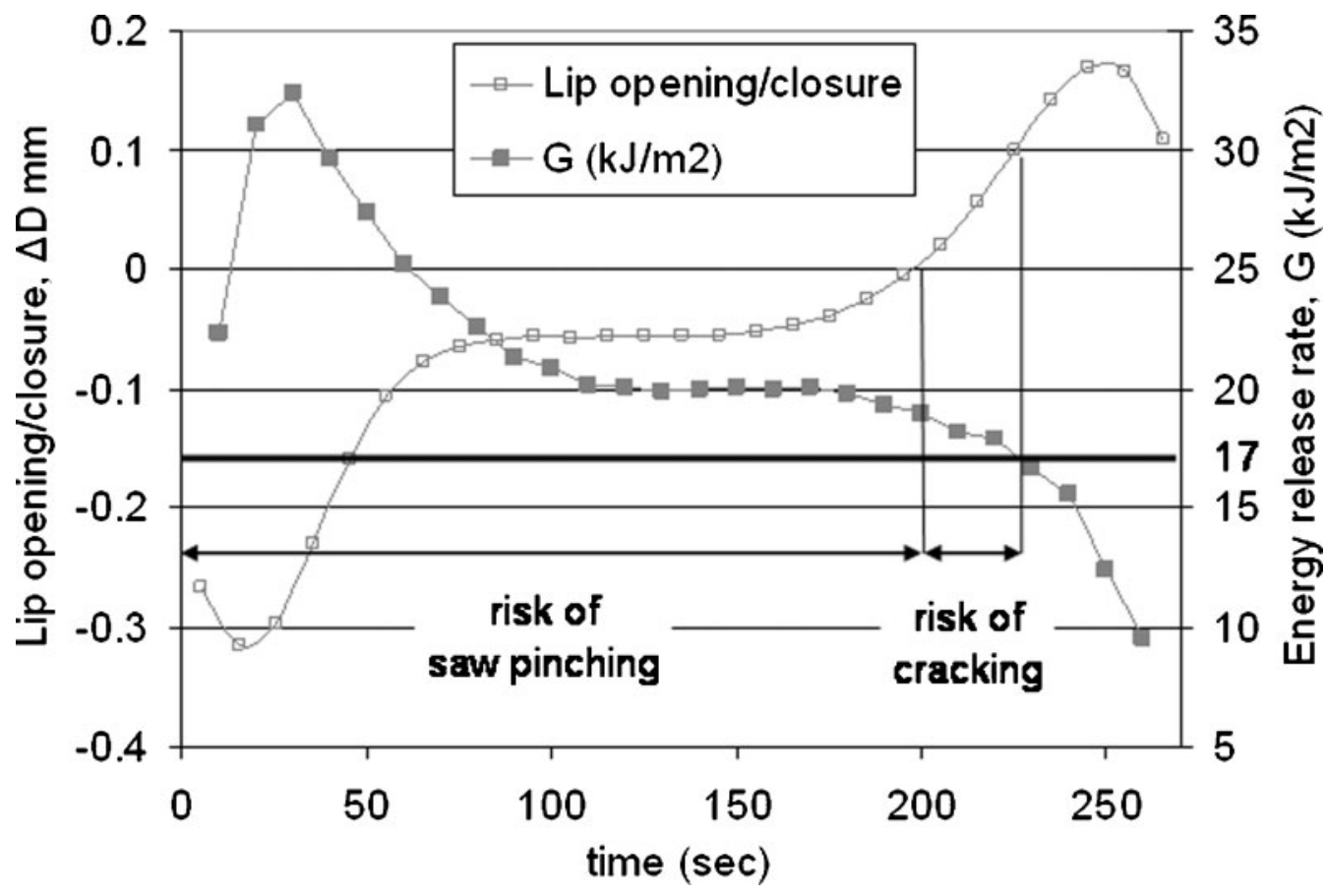

8 Lip opening and rate of energy release during transverse sawing: two possible risks are shown

mesh elements. The new stress field is computed after each step to balance forces and momentums. The temperature increases due to friction between the saw and the ingot is neglected. Figure 7 shows the stress release due to the progression of the $10 \mathrm{~mm}$ thick band saw. The maximum principal stress is represented and a quarter of the ingot is removed in order to see the stress evolution within the ingot.

On the whole, element removal releases some of the strain energy stored in the ingot and both tensile and compressive stresses are lowered close to the saw plane. Nevertheless, the large tensile stresses present in the head of the ingot are unaffected. A local stress increase can be observed in some parts of the ingot where some casting defects may then degenerate into unstable cracks thereby causing the local fracture of the ingot. ${ }^{7}$

\section{Saw pinching and fracture during transverse sawing}

In order to asses the risk of fracture during sawing, the strain energy release approach presented in the section on 'Strain energy release approach' is applied, i.e. the opening of the saw lips is computed as the saw progresses and the strain energy release is calculated according to equation (10).

Figure 8 exhibits the evolution of the lip opening $\Delta D$ and the rate of energy release $G$ as a function of the progression of the saw, i.e. as a function of time. Three distinct regimes of sawing appear; a transient start phase, a steady state in which $\Delta D$ and $G$ are constant and a final transient regime. During the start and steady regimes of sawing, the lips tend to close up and thus the major risk is the pinching of the saw. On the other hand, during the final stage of sawing, the lips tend to open and therefore depending on the value of the critical energy release rate $G^{\mathrm{c}}$, the groove can degenerate into a propagating crack. $G^{\mathrm{c}}$ ranges between 3 and $17 \mathrm{~kJ} \mathrm{~m}^{-2}$ for the AA2024 alloy according to Paramatmuni. ${ }^{20}$ At the very moment when lip opening occurs, $G$ is higher than the maximum critical value of $17 \mathrm{~kJ} \mathrm{~m}^{-2}$ (the toughest case). Therefore the saw groove will always degenerate in a propagating crack. However, a precise value of $G^{\mathrm{c}}$ is required if one wants to be fully predictive. Measurements of the fracture toughness are delicate for the high strength aluminium alloys, because they exhibit rather large values that highly depend on the microstructure. ${ }^{21}$

\section{Influence of cutting groove on rolling faces before transverse sawing}

At the beginning of sawing, the saw has to enter a highly compressive skin (cf. Fig. 6). In order to smoothly relax the internal stresses during sawing, it might be interesting to relax first these high compressive stresses, at least on the rolling faces. In this section, the effect of cutting an $84 \mathrm{~mm}$ deep groove on the rolling faces before transverse sawing is assessed. The comparison with the previous case is presented in Fig. 9 where the lip opening and the strain energy release rate are shown as a function of the progression of the saw through the ingot.

The three distinct regimes of sawing appear again but the lip opening is greatly reduced, especially during the transient start phase. Although the strain energy release is higher during the beginning of sawing, it becomes lower in the steady and final phases. The decrease in the rate of energy release is promising as it reduces the risk of fracture when lip opening occurs. The decrease is substantial, $\sim 4 \mathrm{~kJ} \mathrm{~m}^{-2}$, i.e. $20 \%$. Again, a precise value of $G^{\mathrm{c}}$ is required in order to conclude on the risk of cracking during sawing. Nevertheless, the sawing of two grooves on the rolling faces before transverse sawing could be an interesting alternative in order to reduce the risk of ingot fracture.

\section{Conclusions}

A thermomechanical model of the DC casting process has been extended to simulate butt sawing operations. A new fracture approach during sawing based on the calculation of the strain energy release rate when an 


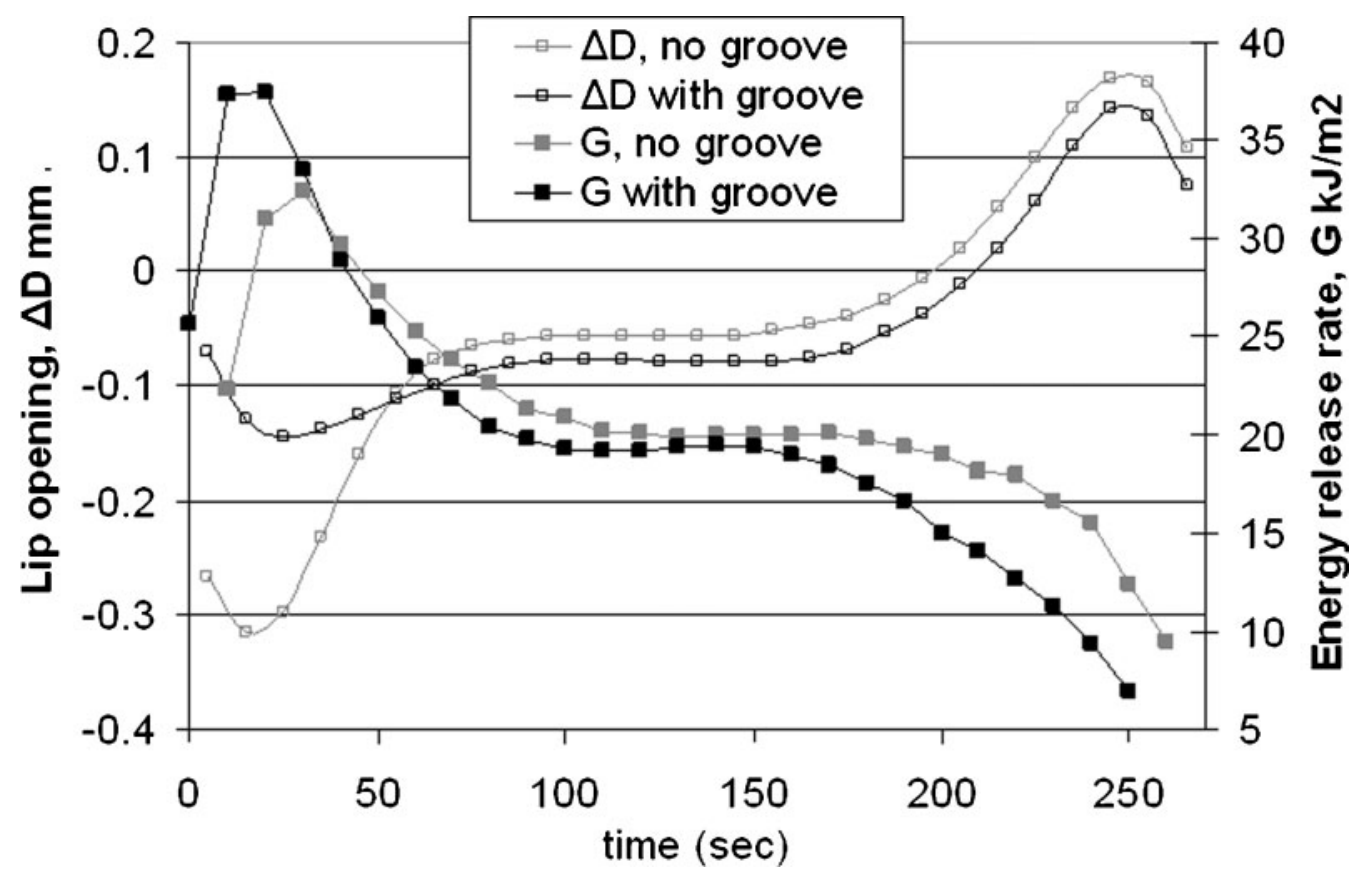

9 Influence of presence of groove on rolling faces, on lip opening and energy release during transverse sawing

element is removed from the model is used to assess the risk of saw pinching or fracture during sawing.

For the AA2024 alloy, it is demonstrated that the suppression of the relaxation treatment before sawing leads to a high risk of saw blocking and cracking, as observed in the industry for those large cross-section ingots. The simulations also show that the sawing of a groove on the rolling faces before transverse sawing appears to be an interesting solution as it reduces the risk of ingot fracture and the contraction of the saw lips.

Nevertheless, it should be pointed out that some refinements of the model are still necessary. In the fracture toughness approach, the interactions of the internal stresses field with a population of stress raisers such as inclusions, pores, microcracks, oxide patches should be considered not only during sawing but also during casting. The fracture approach based on the strain energy release is promise full, provided that fracture toughness data are available and reliable. In this prospect, experimental measurements of this material property on as cast high strength aluminium alloys are still necessary. Other numerical investigations will have to be further validated, notably on ingots with reduced format, before non-relaxed ingots can be sawed safely.

\section{Acknowledgements}

The authors express their deep acknowledgements to the Alcan Fund project no. 0401 for financial support. The active participation of the staff of Alcan, in particular Alcan ATI Valais and Alcan CRV, is also greatly acknowledged. Special thanks go to Benoit Commet from Alcan and Philippe Gilgien from Novelis for their interests in the project.

Based on a presentation at SP07, the 5th Decennial Conference on Solidification Processing, organised by the University of Sheffield, UK on 23-25 July 2007.

\section{References}

1. J.-M. Drezet: 'Direct chill and electromagnetic casting of aluminium alloys: thermomechanical effects and solidification aspects', PhD work no. 1509, EPF-Lausanne, July 1996.
2. J.-M. Drezet and M. Rappaz: Met. Mater. Trans. A, 1996, 27A, 3214-3225.

3. B. Hannart, F. Cialti and R. V. Schalkwijk: in 'Light metals', (ed. A. T. Tabereaux), 879-887; 1994, Warrendale, PA, TMS.

4. H. Fjaer and A. Mo: Met. Mater. Trans. A, 1990, 21A, 1049-1061.

5. J. Sengupta, S. L. Cockcroft, D. M. Maijer and A. Larouche: Mater. Sci. Eng. A, 2005, A397, 157-177.

6. W. Boender, A. Burghardht, E. P. van Klaveren and J. Rabenberg: in 'Light metals', (ed. A. T. Tabereaux), 679-684; 2004, Warrendale, PA, TMS.

7. O. Ludwig, J.-M. Drezet, B. Commet and B. Heinrich: in 'Modeling of casting welding and advanced solidification processes', (ed. C.-A. Gandin and M. Bellet), 185-192; 2006, Warrendale, PA, TMS.

8. C. Sigli, L. Maenner, C. Sztur and R. Shahani: Proc. Int. Conf. on 'Aluminum alloys', (ed. T. Sato, S. Kumai, T. Kobayashi and Y. Murakami), 87-98; 1998, Tokyo, JILM.

9. B. Magnin, L. Maenner, L. Katgerman and S. Engler: Mater. Sci. Forum, 1996, 217-222, 1209-1214.

10. L. Nicolli, A. Mo and M. M'Hamdi: Met. Mater. Trans. A, 2005, 36A, 443-442.

11. G. Jung: 'Thermo mechanical behaviour of AA2017, AA2024 and AA7175 Al Alloys', Internal report, LSMX, EPF Lausanne, Switzerland, July 2006.

12. J.-M. Drezet, M. Rappaz, G.-U. Gruen and M. Gremaud: Metall. Mater. Trans. A, 2000, 31A, 1627-1634.

13. O. Ludwig, J.-M. Drezet, C. L. Martin and M. Suéry: Met. Mater. Trans. A, 2005, 36A, 1525-1535.

14. J. A. Spittle, S. G. R. Brown, J. D. James and R. W. Evans: Proc. 7th Int. Symp. on 'Physical simulation', (ed. H. G. Suzuki, T. Sakai and F. Matsuda), 81-92; 1996, Tsukuba, Japan, National Research Institute for Metals.

15. J.-M. Drezet and M. Rappaz: Proc. 4th Eur. Conf. on 'Residual stresses', (ed. S. Denis et al.), Cluny, France, June 1996, SF2M, Société Française de Métallurgie et Matériaux, 357-366.

16. F. Heymès, B. Commet, B. Dubost, P. Lassince, P. Lequen and G. M. Reynaud: Proc. 1st Int. Non-ferrous Proc. Technol. Conf., St Louis, MO, USA, March 1997, ASM, International, ASMHeat Treating Society.

17. H. D. Bui: 'Mécanique de la rupture fragile'; 1978, Paris, Masson.

18. J. Lu (ed.): 'Handbook of measurement of residual stresses'; 1996, Lilburn, GA, Society for Experimental Mechanics, Inc., The Fairmont Press.

19. J. Lemaître and J.-L. Chaboche: 'Mécanique des matériaux solides'; 1988, Paris, Dunod.

20. R. K. Paramatmuni, K.-M. Chang, B. S. Kang and X. Liu: Mater. Sci. Eng. A, 2004, A379, 293-301.

21. M. O. Lai and W. G. Fergusson: Mater. Sci. Eng., 1985, 74, 133138. 